\title{
A Micro Pump Driven by a Thin Film Permanent Magnet*
}

\author{
Chao ZHI**, Tadahiko SHINSHI** and Minoru UEHARA*** \\ **Interdisciplinary Graduate School of Science and Engineering, Tokyo Institute of Technology, R2-38, \\ 4259 Nagatsuta-cho, Midori-ku, Yokohama, 226-8503, Japan \\ E-mail: shinshi@pi.titech.ac.jp \\ ${ }^{* * *}$ Magnetic Materials Research Laboratory, Hitachi Metals, Ltd., 2-15-17 Egawa, Shimamoto-cho, \\ Mishima-Gun, Osaka, 618-0013, Japan
}

\begin{abstract}
A valveless micro pump, utilizing a multi-layer thin film $\mathrm{NdFeB} / \mathrm{Ta}$ permanent magnet (TFPM), is presented. The micro pump consists of a diaphragm actuator, comprising a TFPM, $6 \mu \mathrm{m}$ in thickness and $3 \mathrm{~mm}$ in diameter, which is bonded to a membrane made of polydimethylsiloxane (PDMS) of about $80 \mu \mathrm{m}$ in thickness, together with a pump chamber and a pair of diffuser elements. TFPM is sputtered on a $50 \mu \mathrm{m}$ thick $\mathrm{Nb}$ sheet. The diffuser elements are used to generate a one-way fluid flow. The chamber is made of acryl plates. UV negative film resist is used to bond the different layers. Compared to sinusoidal driving signal with same amplitude, a square driving signal can generate a higher flow rate. Applying a square wave voltage, $\pm 7.5 \mathrm{~V}$ in amplitude, the pump flow rate attains $130 \mu \mathrm{L} / \mathrm{min}$ at a frequency of $15 \mathrm{~Hz}$. The flow rate is highly dependent on frequency and driving signal type. Diaphragm displacement, pump frequency is measured and analyzed.
\end{abstract}

Key words: Valveless Micro Pump, Thin Film Permanent Magnet, Diffuser, Electromagnetic Actuation, Square Wave Signal

\section{Introduction}

Micro fluidics is a rapidly developing research area and can be applied into various fields such as chemicals, biotechnology and medical electronics ${ }^{(1)}$. A micro pump provides the actuation source in micro fluidics systems ${ }^{(2)}$. Since the first pump designed in the $1980 \mathrm{~s}^{(3)}$, different types of the micropump have been developed ${ }^{(3)-(6)}$. Among these, the displacement valveless pumps have the advantage of simple design and fabrication, as well as the avoidance of clogging when pumping cells or particles. The actuation principles of micro pumps can be divided into piezo-electric, electrostatic, electromagnetic, thermo pneumatic and shape memory effect ${ }^{(6)-(10)}$. Compared with other forms of actuator, an electromagnetic actuator can provide a relatively larger force with a smaller input voltage, as a large membrane deflection and thus large stroke volume can be achieved. Research into valveless micro pumps using electromagnetic actuators on polydimethylsiloxane (PDMS) membranes by Yamahata et al. ${ }^{(11)}$ and Dau et al. ${ }^{(12)}$ demonstrated flow rates of about several hundreds $\mu \mathrm{L} / \mathrm{min}$ with large membrane deflections (several hundreds $\mu \mathrm{m}$ ). The force was in the range of several hundreds $\mu \mathrm{N}$ to several $\mathrm{mN}$ with input voltages of several volts.

For MEMS pumps utilizing electromagnetic actuation, many use thick permanent magnets as actuators. Usually the thickness of the magnetic actuator is more than $1 \mathrm{~mm}$ due to the limitations of permanent magnet machining. The thick permanent magnet is a limitation in decreasing device size. Lee et al. ${ }^{(8)}$ proposed an integrated magnetic

*Received 4 Apr., 2012 (№. 12-0168) [DOI: 10.1299/jamdsm.6.1180]

Copyright $(\subseteq) 2012$ by JSME 
diaphragm using an electroplated CoNiMnP permanent magnet to decrease the thickness of the magnetic film to $60 \mu \mathrm{m}$. However, the small residual flux density $(\sim 0.2 \mathrm{~T})$ of the electroplated CoNiMnP magnet ${ }^{(13)}$ limits the actuation force with small thicknesses.

Recently, $\mathrm{NdFeB} / \mathrm{Ta}$ thin film permanent magnets (TFPM) of several $\mu \mathrm{m}$ in thickness, reported by Uehara ${ }^{(14)(15)}$, exhibited superior magnetic properties equivalent to those of bulk permanent material. The high residual flux density $(\sim 1.4 \mathrm{~T})$ and high coercivity $(\sim 1 \mathrm{MA} / \mathrm{m})$ as well as a high temperature resistance ${ }^{(20)}\left(\sim 165^{\circ} \mathrm{C}\right)$ enable it to be integrated into MEMS technology.

This work describes the design, fabrication, and analysis of a valveless micro pump utilizing a thin film permanent magnet. In this paper, magnetic flux density of the TFPM and force between coil and TFPM have been simulated. A thin film multilayer $\mathrm{NdFeB} / \mathrm{Ta}$ was deposited on a $50 \mu \mathrm{m}$ thick $\mathrm{Nb}$ sheet using a sputtering process. PDMS of about $80 \mu \mathrm{m}$ in thickness was used as the membrane. The chamber and other parts were fabricated on acryl plate by laser cutting. The diaphragm performance was tested using external electromagnetic actuation. The diaphragm displacement was measured and diaphragm stiffness was calculated. Inputting of sinusoidal and square wave signals, the diaphragm displacement was measured and diaphragm velocity was also analyzed. The flow rate was measured with input of both sinusoidal and square waves. By applying the model established by Pan et al. ${ }^{(18)}$, the calculated resonant frequency of flow rate fitted well with the measured frequency at peak flow rate.

\section{Pump Mechanism and Structure}

Figure 1 shows the working principle of the pump. The pump consists of an electromagnet and a pump chip. TFPM of $\mathrm{NdFeB} / \mathrm{Ta}$ is bonded on a diaphragm. The external coil with a core is placed beneath the pump chip. When a current is input into the coil, electromagnetic force will be generated between the coil and TFPM, thus the diaphragm deforms. Once current direction changes, the membrane moves in the opposite direction. Diffuser components are used to connect the chamber with an inlet and an outlet. It has been proved that, for a certain range of expanding angle, the diffuser has a smaller fluidic resistance in the expanding direction, while it has a larger fluidic resistance in the converging direction ${ }^{(16)}$. This results in more liquid flowing into the chamber from the inlet than from the outlet. When the diaphragm moves downwards, more liquid flows out from the outlet. After a complete pump cycle, a net flow is generated from the inlet to the outlet.

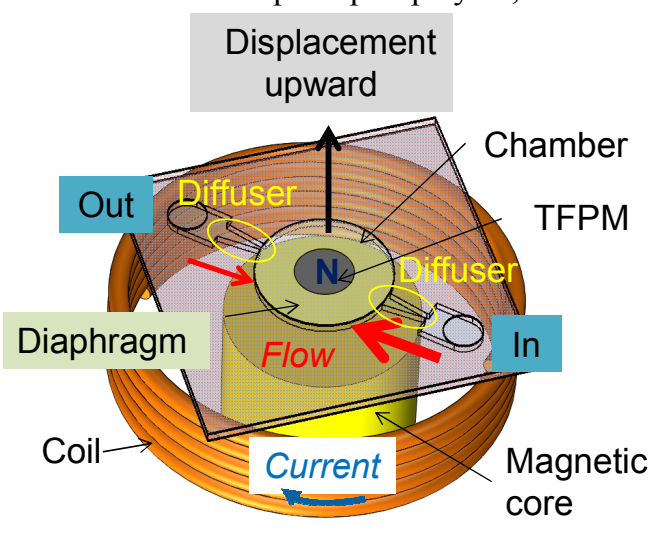

(a) Upward motion

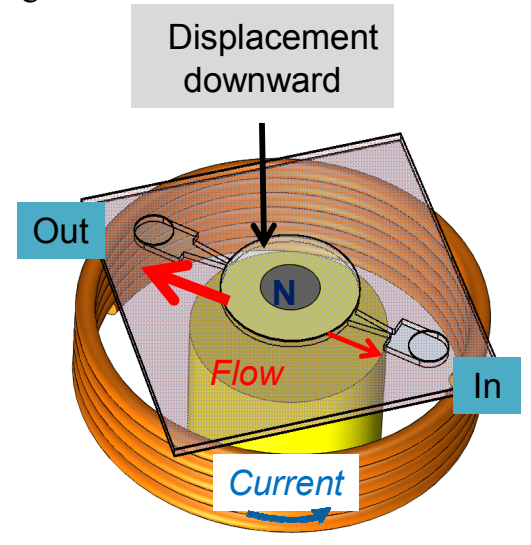

(b) Downward motion

Fig. 1 Micro pump mechanism

In this paper, Fig. 2(a) and Fig. 2(b) show the top and bottom views of the designed pump chip, and Fig. 2(c) is the A-A cross section of the designed pump. A diaphragm made of PDMS is $7 \mathrm{~mm}$ in diameter and $80 \mu \mathrm{m}$ in thickness; TFPM material, $\Phi 3 \mathrm{~mm} \times 6 \mu \mathrm{m}$, is 
bonded to the PDMS diaphragm. Top and bottom plates, together with a chamber/channel part, are made of acryl. An electromagnet with an iron core in the center is placed beneath the TFPM. The channel geometrical parameters are shown in Fig. 2(d), the diffuser's narrowest width is $d_{1}=100 \mu \mathrm{m}$, the broadest width $d_{2}=500 \mu \mathrm{m}$ and length $\mathrm{L}=2300 \mu \mathrm{m}$. The curvature radius in the narrowest neck is $\mathrm{r}=100 \mu \mathrm{m}$.

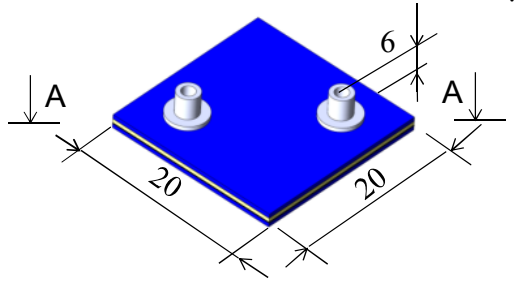

(a) Top view

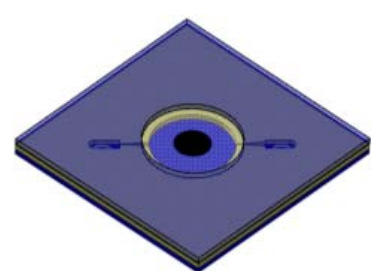

(b) Bottom view

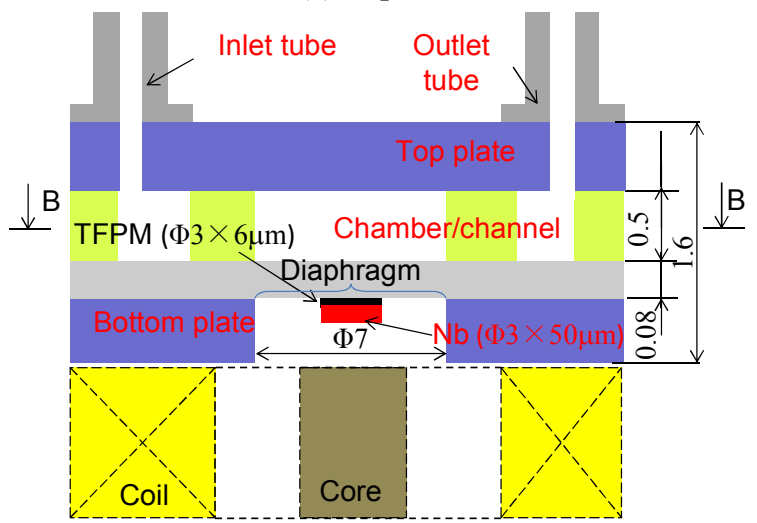

(c) A-A cross section of the pump chip (d) B-B cross section of the pump chip

Fig. 2 Pump structure

\section{TFPM Sheet}

$\mathrm{NdFeB} / \mathrm{Ta}$ multilayer TFPM of $6 \mu \mathrm{m}$ in thickness is deposited by magnetron sputtering through a Ti hard mask. A $200 \mathrm{~nm} \mathrm{NdFeB}$ layer and $10 \mathrm{~nm}$ Ta layer are deposited sequentially at $480^{\circ} \mathrm{C}$ to form a thin film. The sputtering temperature exceeds PDMS's temperature limitation $\left(\sim 200^{\circ} \mathrm{C}\right)$ so that directly depositing TFPM on PDMS is impossible. An alternative method is to sputter TFPM on a metal sheet, followed by bonding with a PDMS membrane. Four types of metal sheet $(12 \mu \mathrm{m} \mathrm{Al}, 10 \mu \mathrm{m} \mathrm{Cu}, 15 \mu \mathrm{m} \mathrm{Nb}$ and $50 \mu \mathrm{m} \mathrm{Nb})$ were tested as the substrates for sputtering TFPM. Table 1 shows the TFPM magnetic properties on four types of substrate compared with a typical $\mathrm{SiO}_{2}$ substrate. The heat resistance of TFPM defined by Uehara et al. ${ }^{(20)}$ is about $165^{\circ} \mathrm{C}$ for a $\mathrm{SiO}_{2}$ substrate. For the Al substrate, damage occurs in the sputtered areas. The temperature at the sputtered area should be higher than $480^{\circ} \mathrm{C}$, which is close to the melting point of $\mathrm{Al}\left(650^{\circ} \mathrm{C}\right)$. $\mathrm{Cu}$ sheet can resist high temperature, however, the diffusion of $\mathrm{Cu}$ into $\mathrm{NdFeB}$ decreases the coercivity to around $0.6 \mathrm{MA} / \mathrm{m}$. The heat resistance also decreases from $\sim 160^{\circ} \mathrm{C}$ to less than $90^{\circ} \mathrm{C}$.

Table 1 TFPM characteristics on different substrates after sputtering

\begin{tabular}{|c|c|c|c|c|c|}
\hline \multicolumn{2}{|c|}{ Substrate } & \multicolumn{3}{c|}{ Magnetic property } & \multirow{2}{*}{ Comment } \\
\cline { 1 - 5 } Material & Thickness & $\begin{array}{c}\text { Residual } \\
\text { flux density }\end{array}$ & Coercivity & Heat resistance & \\
\hline $\mathrm{SiO}_{2}$ & - & $1.25 \mathrm{~T}$ & $1.32 \mathrm{MA} / \mathrm{m}$ & $165^{\circ} \mathrm{C}$ & Typical substrate \\
\hline $\mathrm{Al}$ & $12 \mu \mathrm{m}$ & NA & NA & NA & Damaged \\
\hline $\mathrm{Cu}$ & $10 \mu \mathrm{m}$ & $1.20 \mathrm{~T}$ & $0.6 \mathrm{MA} / \mathrm{m}$ & $<90^{\circ} \mathrm{C}$ & Low coercivity \\
\hline \multirow{2}{*}{$\mathrm{Nb}$} & $15 \mu \mathrm{m}$ & $1.30 \mathrm{~T}$ & $1.25 \mathrm{MA} / \mathrm{m}$ & $>90^{\circ} \mathrm{C}$ & Surface deformation \\
\cline { 2 - 5 } & $50 \mu \mathrm{m}$ & $1.32 \mathrm{~T}$ & $1.05 \mathrm{MA} / \mathrm{m}$ & $>90^{\circ} \mathrm{C}$ & \\
\hline
\end{tabular}


The $\mathrm{Nb}$ sheet of $15 \mu \mathrm{m}$ in thickness can maintain the TFPM magnetic property, however, the residual stress after sputtering deforms the TFPM, as shown in Fig. 3. Thus $\mathrm{Nb}$ sheet of $50 \mu \mathrm{m}$ was finally chosed.

TFPM magnetic flux density was first simulated with finite element method (FEM) electromagnetic field simulation software (Maxwell 3D, Ansys Inc.) and then practically evaluated with a gauss meter (Type 6010, F. W. Bell. Inc.). The Hall element in the Gauss probe is $310 \mu \mathrm{m}$ away from the measuring surface. So the magnetic flux density in the plane of $310 \mu \mathrm{m}$ distance above the surface of TFPM was measured. For the bonding of pump different layers, film resist was to be utilized and baking temperature of about $90^{\circ} \mathrm{C}$ was needed. Furthermore, the TFPM works in magnetic field generated by a coil $(\sim 0.1 \mathrm{MA} / \mathrm{m})$; coercivity needed also to be large enough to maintain the magnetic property. With a $\mathrm{Cu}$ substrate, the magnetic flux density after sputtering was lower than the simulated value. Due to the low coercivity, the measured magnetic flux density decreased after placing in magnetic field of $0.32 \mathrm{MA} / \mathrm{m}$. Heat treatment of $90^{\circ} \mathrm{C}$ also decreased the magnetic flux density. The $\mathrm{Nb}$ substrate was shown to be excellent in keeping the magnetic property of the TFPM.

Table 2 TFPM characteristics on different substrates after assembled in the pump

\begin{tabular}{|c|c|c|c|c|c|}
\hline \multicolumn{2}{|c|}{ Substrate } & \multicolumn{4}{|c|}{$\begin{array}{l}\text { Maximum magnetic flux density } \\
310 \mu \mathrm{m} \text { from the substrate surface }\end{array}$} \\
\hline Material & Thickness & Simulated & $\begin{array}{r}\text { Measured } \\
\text { after } \\
\text { sputtering }\end{array}$ & $\begin{array}{c}\text { Measured } \\
\text { after placed in outer } \\
\text { magnetic field }(0.32 \mathrm{MA} / \mathrm{m})\end{array}$ & $\begin{array}{l}\text { Measured } \\
\text { after } 90^{\circ} \mathrm{C} \\
\text { heat }\end{array}$ \\
\hline $\mathrm{Al}$ & $12 \mu \mathrm{m}$ & \multirow{4}{*}{$2.83 \mathrm{mT}$} & NA & - & NA \\
\hline $\mathrm{Cu}$ & $10 \mu \mathrm{m}$ & & $1.23 \mathrm{mT}$ & $0.9 \mathrm{mT}$ & $0.48 \mathrm{mT}$ \\
\hline \multirow{2}{*}{$\mathrm{Nb}$} & $15 \mu \mathrm{m}$ & & $1.93 \mathrm{mT}$ & $1.93 \mathrm{mT}$ & $1.93 \mathrm{mT}$ \\
\hline & $50 \mu \mathrm{m}$ & & $2.23 \mathrm{mT}$ & $2.23 \mathrm{mT}$ & $2.23 \mathrm{mT}$ \\
\hline
\end{tabular}
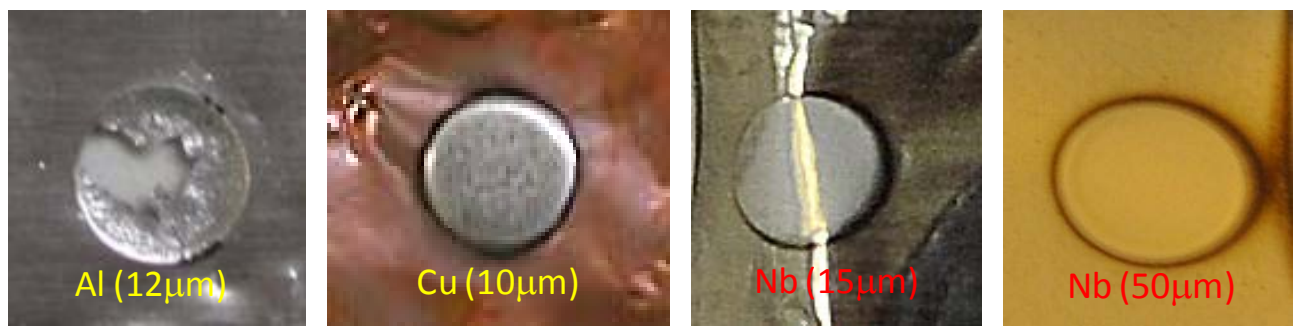

Fig. 3 Sputtered TFPM on four kinds of substrates

For the TFPM on $50 \mu \mathrm{m} \mathrm{Nb}$ substrate, Fig. 4 indicates the simulated and measured magnetic flux density in the plane $310 \mu \mathrm{m}$ above TFPM surface.

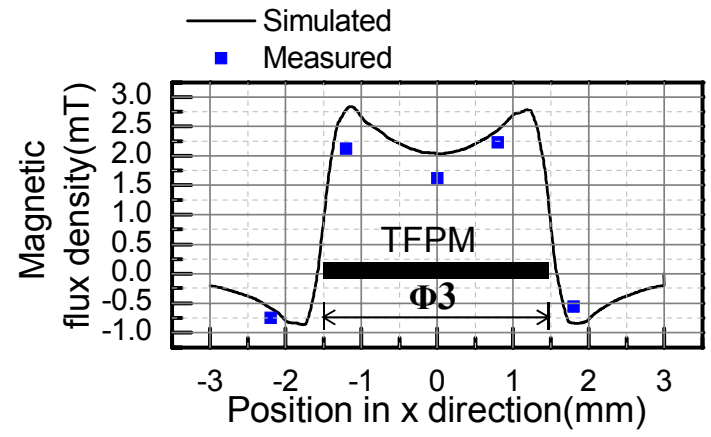

Fig. 4 TFPM surface magnetic flux density 


\section{Pump Fabrication}

For the fabrication of the top and bottom plates, as well as the channel/chamber plate of the pump chip, a $\mathrm{CO}_{2}$ laser cutting machine (L-906PC, IIDA KOGYO Co.) was used. The PDMS (SIM-260, Shin-Etsu Chemical Co., Japan) membrane was fabricated by spin coating, followed by curing at $150^{\circ} \mathrm{C}$ for half an hour. The thickness, measured using a microscope (VW-6000SP, Keyence Co.) was $83 \mu \mathrm{m}$.

The fabricated diffuser part is shown in Fig. 5. The diffuser had the narrowest width of $190 \mu \mathrm{m}$, broadest width of $573 \mu \mathrm{m}$ and length of $2100 \mu \mathrm{m}$.

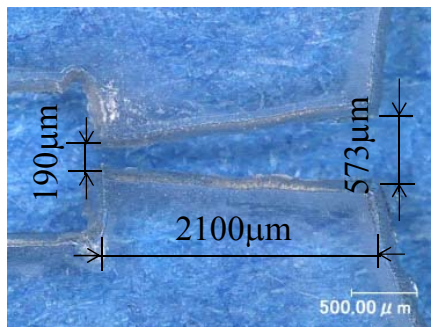

Fig. 5 Fabricated diffuser part

Negative film photoresist (PerMX3000, DuPont Co., Ltd, USA) with a thickness of $20 \mu \mathrm{m}$ was used to bond each plate and the PDMS film. The TFPM on the Nb substrate was bonded to the PDMS membrane using additional uncured PDMS. The bonding process lasted for 9 hours at $90^{\circ} \mathrm{C}$. Figure 6 shows top view and bottom view of the fabricated pump chip.

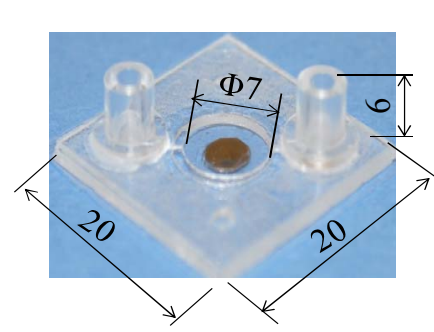

(a) Top view

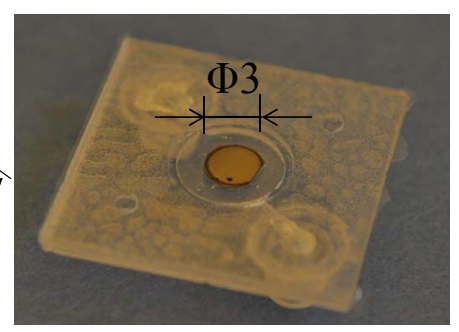

(b) Bottom view

Fig. 6 Fabricated micro pump

\section{Pump Test}

\subsection{Actuator Test}

The displacement characteristic of the diaphragm was measured experimentally using a fiber displacement sensor (Model D20, PHITEC, Inc.), as shown in Fig. 7. In this test, the chamber was not filled with liquid. In order to place the fiber displacement sensor under the TFPM and apply driving magnetic flux to the TFPM, a coreless coil of around 1500 turns was used, having an inner diameter of $5 \mathrm{~mm}$, an outer diameter of $75 \mathrm{~mm}$ and thickness of $35 \mathrm{~mm}$.

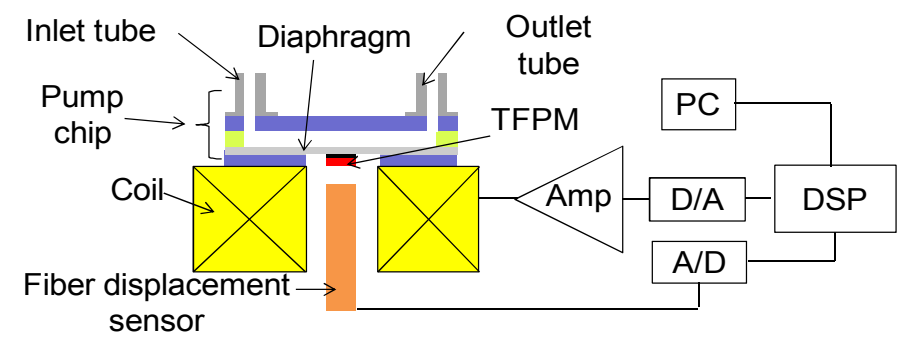

Fig. 7 Diaphragm displacement test setup 


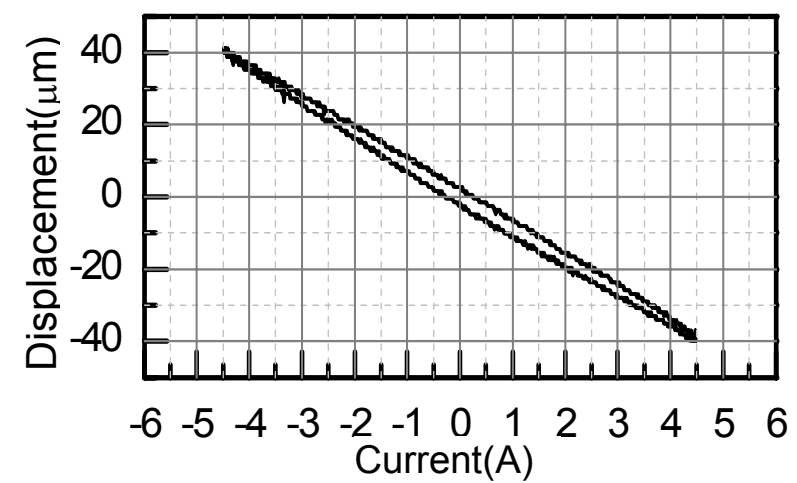

Fig. 8 Static relationship between diaphragm displacement and current

Figure 8 shows the static characteristic of the diaphragm. The force generated between the TFPM and coil was simulated by the Maxwell software. The simulated force was around $270 \mu \mathrm{N}$ when the gap between coil surface and TFPM was $0.5 \mathrm{~mm}$ and coil input current $2 \mathrm{~A}$. The measured displacement was about $15 \mu \mathrm{m}$ to $20 \mu \mathrm{m}$. Thus the stiffness of the diaphragm was calculated to be in the range of $13 \mathrm{~N} / \mathrm{m}$ to $18 \mathrm{~N} / \mathrm{m}$.

\subsection{Signal and Liquid Effect to Displacement}

Inputting two types of signal (sinusoidal wave and square wave, amplitude $\pm 7.5 \mathrm{~V}, 1 \mathrm{~Hz}$ ) into the coil, the diaphragm displacement was measured by a fiber displacement sensor. The output analog signal was converted by a 12 bit A/D converter at a sampling frequency of $1 \mathrm{kHz}$. The chamber was either filled or empty of fluid. To avoid the bubbles in the chamber, ethanol was used as the liquid because of its low surface tension.

Figure 9 shows the diaphragm deflection with and without the liquid.

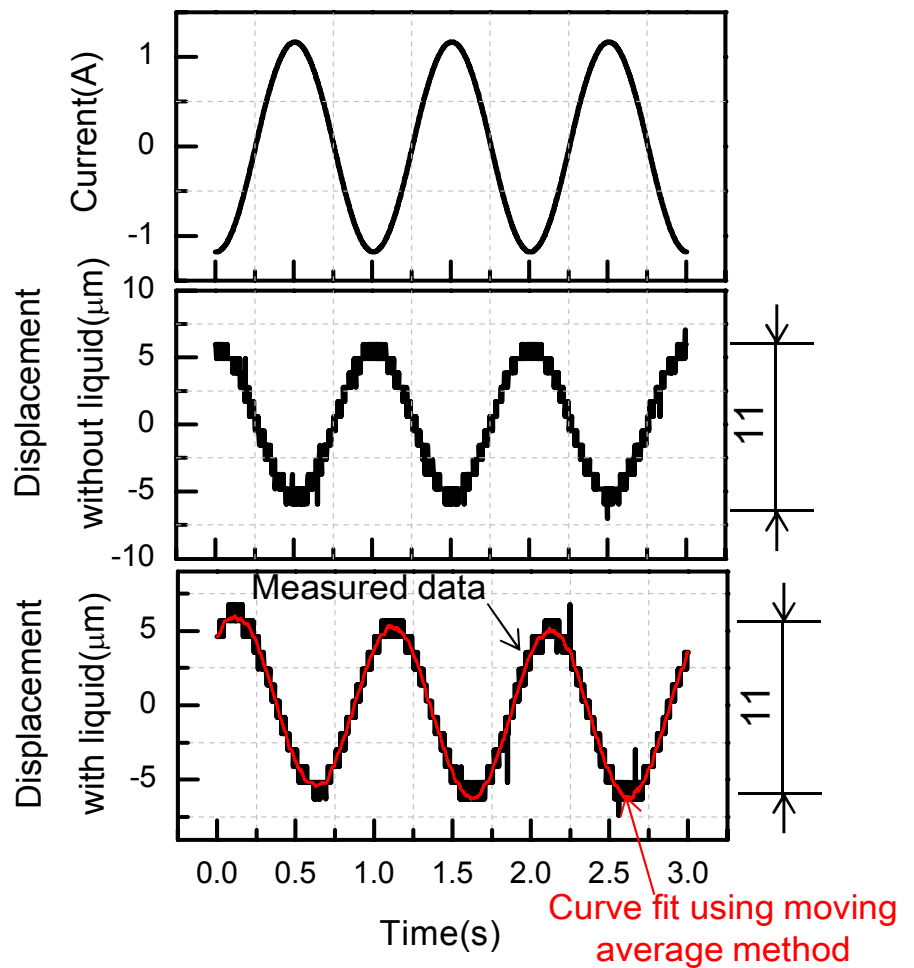

(a) Diaphragm displacement with a sinusoidal driving signal 


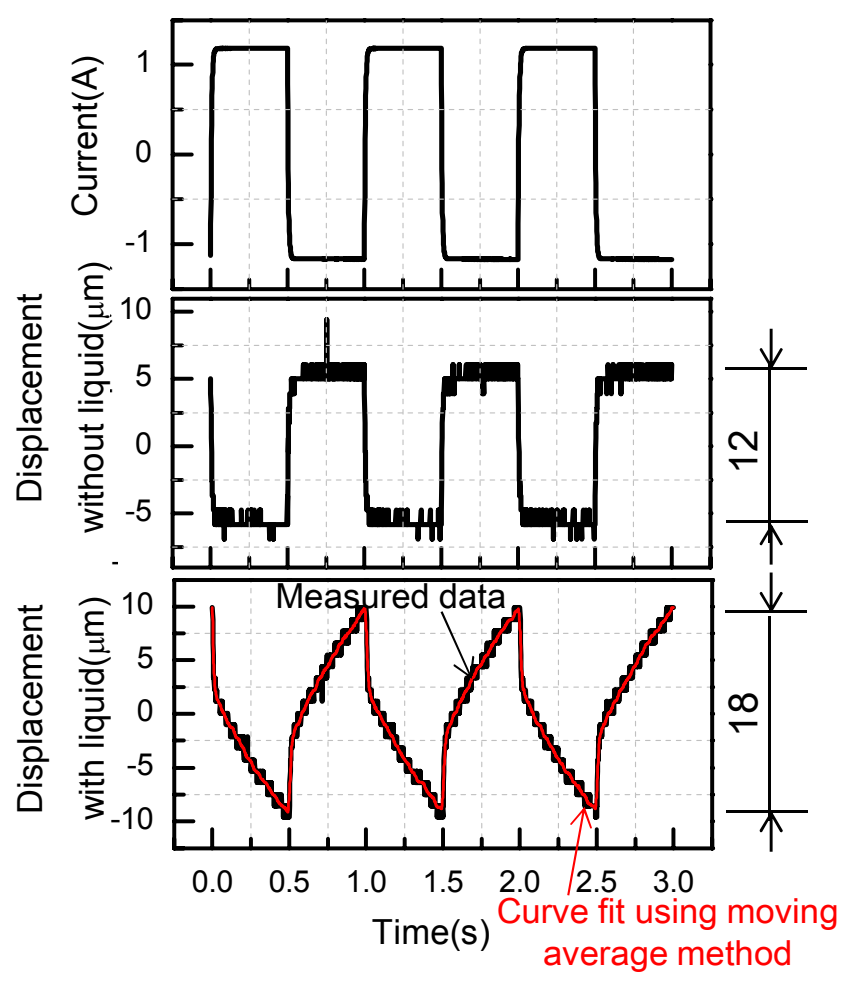

(b) Diaphragm displacement with a square driving signal Fig. 9 Diaphragm deflection with and without liquid

For the sinusoidal signal input, the deflection was not much different with and without liquid. A phrase lag and delay of the response existed between the driving signal and the measured displacement, this may due to the fluid inertia property. However, for the square wave signal, the diaphragm deflection with liquid was larger than that without liquid. The deflection increased from $12 \mu \mathrm{m}$ to $18 \mu \mathrm{m}$. Analysis of this phenomenon will be researched in the future.

\subsection{Pump Performance}

Figure 10 shows the experimental setup for the flow rate measurement. The pump was filled with ethanol. Sinusoidal or square wave voltages were input into the coil. The coil with an iron core was utilized to increase the flux density and the diaphragm displacement. The amplitude of the voltage signal was $\pm 7.5 \mathrm{~V}$ and the frequency ranged from 1 to $100 \mathrm{~Hz}$. The flow rate was calculated by observing the liquid height variation within a certain period of time. Mainly due to the liquid height measuring resolution, the flow rate resolution is limited to around $\pm 1.2 \mu \mathrm{L} / \mathrm{min}$.

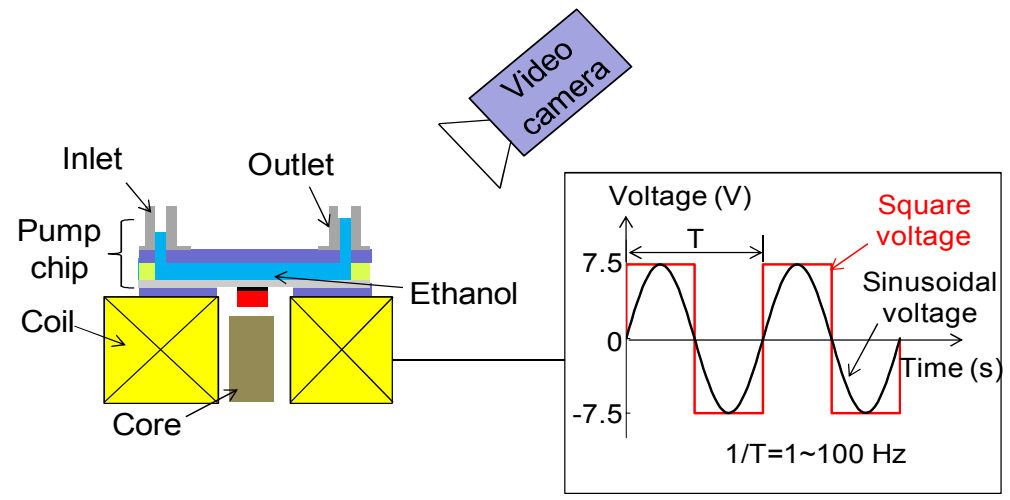

Fig. 10 Flow rate measurement setup and input signals 


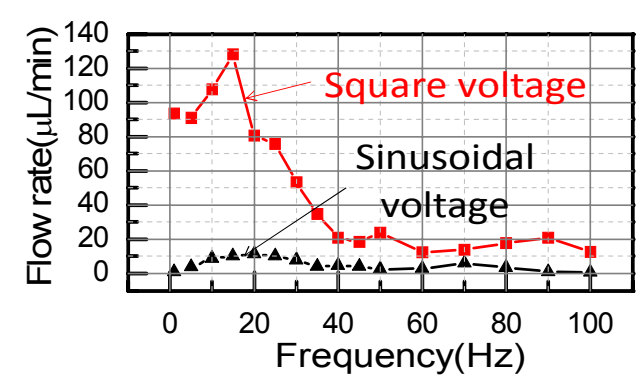

Fig. 11 Frequency depended flow rate

The measured flow rate result is shown in Fig. 11. The flow rate when applying square and sinusoidal voltages attained peaks of $130 \mu \mathrm{L} / \mathrm{min}$ at $15 \mathrm{~Hz}$, and $12 \mu \mathrm{L} / \mathrm{min}$ at $20 \mathrm{~Hz}$, respectively. The flow rate difference between two types of signal may be induced by the diaphragm velocity changes.

Smooth operation of the diaphragm displacement with the chamber filled with liquid was achieved, as noted in Fig. 9. The velocity of the diaphragm could be calculated by applying differential operation of the smoothed displacement signal, as shown in Fig. 12. For the sinusoidal signal, the maximum velocity during a period was about $50 \mu \mathrm{m} / \mathrm{s}$, while for the square wave signal, the maximum velocity was calculated to be $350-400 \mu \mathrm{m} / \mathrm{s}$, being a factor of about 7 larger than that with the sinusoidal signal. Mane et al. ${ }^{(19)}$ also mentioned this phenomenon of waveform dependence in piezoelectric actuated diaphragms. In Ref [19], the diaphragm velocity caused by square signal is around 5 6 times larger than that of sinusoidal signal. The reason of the velocity difference caused by driving signal type would be further considered in the next period of work.

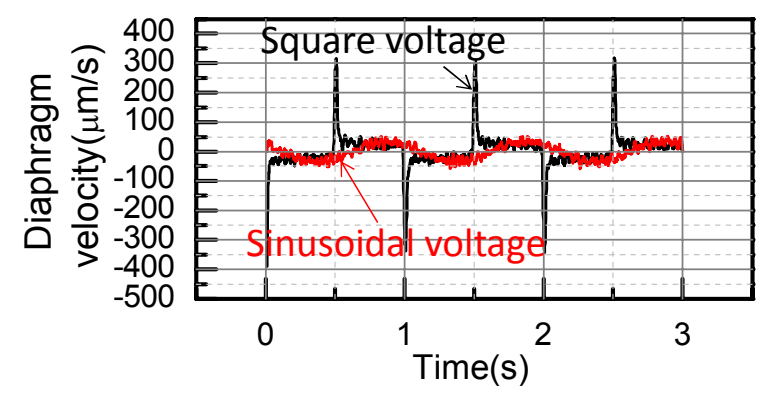

Fig. 12 Diaphragm velocity related with input of two types of signals

\subsection{Resonant Frequency of Flow Rate}

Pan et al. ${ }^{(18)}$ proposed the following formula for calculating the flow rate resonance frequency of a diffuser type pump.

$$
\begin{aligned}
& f_{0}=\frac{f_{1}}{\sqrt{1+R_{p}\left[\frac{D}{h}+\frac{\left(1+\alpha^{2}\right) L A_{m}}{2 h \sqrt{A_{1} A_{2}}}\right]}} \\
& \alpha=\frac{\eta^{0.5}-1}{\eta^{0.5}+1}
\end{aligned}
$$

The frequency response of the coil current to voltage is shown in Fig. 13; $f_{1}$ is the diaphragm resonant frequency, which was measured to be $648 \mathrm{~Hz}$ using a frequency response analyzer (FRA5022, NF, Corp.), as shown in Fig. 14; the coil cut off frequency is $14 \mathrm{~Hz} . \mathrm{R}_{\mathrm{p}}$ is the density ratio between pumping liquid and membrane material. $\mathrm{D}$ is the 
chamber height and $\mathrm{h}$ is the diaphragm height. $\alpha$ is calculated from Eq. (2), in which $\eta$ is the pressure loss coefficient, here we assume $\eta$ to be 2.5 according to Olsson et al. ${ }^{(17)}$. $\mathrm{A}_{1}$ is the diffuser narrowest cross area, $A_{2}$ the broadest and $A_{m}$ the diaphragm area. The calculated pump frequency was around $18 \mathrm{~Hz}$, which is close to the frequency at which the peak flow rate was achieved.
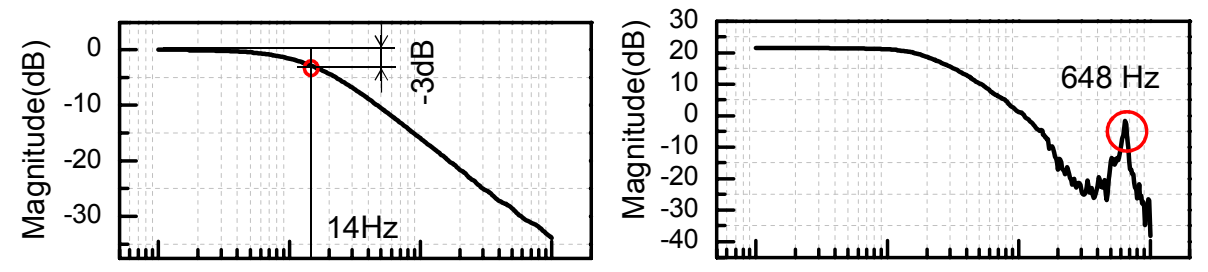

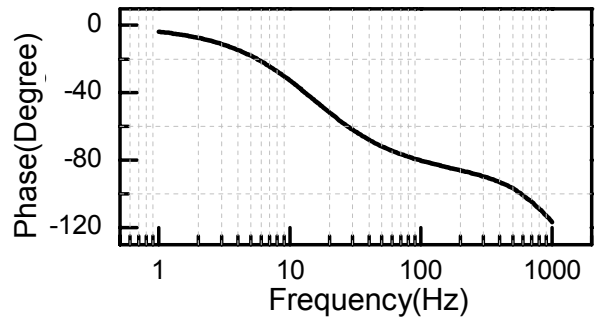

Fig. 13 Frequency response from coil input voltage to current

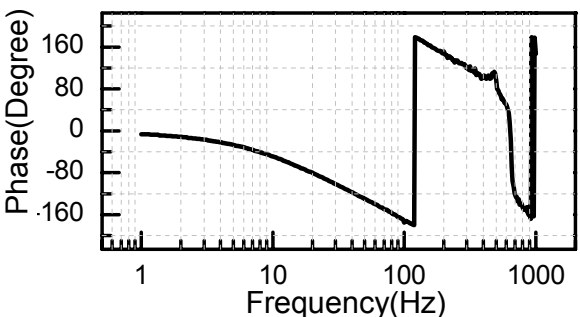

Fig. 14 Frequency response from input voltage to diaphragm displacement

\section{Conclusion and Future Work}

A micro pump utilizing a TFPM, PDMS membrane, and diffusers was proposed and fabricated. A maximum flow rate of $130 \mu \mathrm{L} / \mathrm{min}$ was realized by applying a square wave with peak to peak amplitude of $\pm 7.5 \mathrm{~V}$ at a frequency of $15 \mathrm{~Hz}$. A method of attaching TFPM on PDMS membrane was proposed. The frequency of the peak flow rate showed good agreement with the resonant frequency in the model of Pan et al. ${ }^{(18)}$. Signal type dependent flow rate was measured and analyzed. A square wave driving signal was experimentally demonstrated to have a better effect in generating a high fluid flow rate.

For future work, channel precision will be improved and a micro coil in the scale of around $10 \mathrm{~mm}$ will be designed and utilized for driving the TFPM actuator. Driving signal type dependent flow rate will also be theoretically researched.

\section{References}

(1) Nguyen N. and Wereley S., Fundamentals and Applications of Microfluidics, 2nd ed., (2006), pp.1-9, Artech House.

(2) Amirouche, F., Zhou, Y., Tom, J., Current micropump technologies and their biomedical applications, Microsystem Technologies, Vol.15, No.5(2009), pp. 647-666.

(3) Smith, J., "Piezo-Electrical Micropump", Netherlands. E. Patent, EP0134614(1984).

(4) Wallman, L. Ekstrom, S., Marko-Varga, G., Laurell, T., Nilsson, J., Autonomous protein sample processing on-chip using solid-phase microextraction, capillary force pumping, and microdispensing., Electrophoresis, Vol.25, No.21-22(2004), pp. 3778-3787.

(5) Suzuki, H., Yoneyama, R., Integrated microfluidic system with electrochemically actuated on-chip pumps and valves, Sensor and Actuators B, Vol.96, No.1-2(2003), pp. $38-45$.

(6) Olsson, A., Enoksson, P., Stemme, G., Stemme, E., A valve-less planar pump isotropically etched in silicon, J. Micromech. Microeng., Vol.6, No.1(1996), pp. 87-91.

(7) Zengerle, R., Richter, A., Sandmaier, H., A micro membrane pump with electrostatic actuation., Proceedings of Micro Electro Mechanical Systems, Travemunde, Germany (1992-2), pp. 19-24.

(8) Lee, C., Chen, Z., Valveless impedance micropump with integrated magnetic diaphragm, 
Biomed Microdevices, Vol.12, No.2(2010), pp. 197-205.

(9) Xu, D., Wang, L., Ding, G., Zhou, Y., Yu, A., Cai, B., Characteristics and fabrication of NiTi/Si diaphragm micropump, Sensors and Actuators A, Vol.93, No.1(2001), pp. 87-92.

(10) Kim, J., Na, K., Kang, C., Kim, Y., A disposable thermopneumatic-actuated micropump stacked with PDMS layers and ITO-coated glass, Sensors and Actuators. A, Vol.120, No.2(2005), pp. 365-369.

(11) Yamahata, C., Lotto, C., Al-Assaf, E., Gijs, M., A PMMA valveless micropump using electromagnetic actuation, Microfluidics and Nanofluidics, Vol.1, No.3(2005), pp. 197-207. (12) Dau, V., Dinh, T., Nguyen, X., Amarasinghe, R., Tanaka, K., Sugiyama, S., Microfluidic Valveless Pump Actuated by Electromagnetic Force, Proceedings of IEEE SENSORS, (2009-10), pp. 679-682.

(13) Sun, X., Yuan, Q., Fang, D., Zhang, H., Electrodeposition and characterization of CoNiMnP permanent magnet arrays for MEMS applications, proceedings of the 16th Nano/Micro Engineered and Molecular Systems (IEEE-NEMS), (2011-6), pp. 367-371.

(14) Minoru, U., Microstructure and permanent magnet properties of a perpendicular anisotropic $\mathrm{NdFeB} / \mathrm{Ta}$ multilayered thin film prepared by magnetron sputtering, Journal of Magnetism and Magnetic Materials, Vol.284(2004), pp. 281-286.

(15) Minoru, U., Gennai, N., Fujiwara, M., Tanaka, T., Improved perpendicular anisotropy and permanent magnet properties in Co-doped Nd-Fe-B films multilayered with Ta, IEEE Transactions on Magnetics, Vol.41, No.10(2005), pp. 3838-3843.

(16) Stemme, E., Stemme, G., A valveless diffuser/nozzle-based fluid pump, Sensors and Actuators A, Vol.39, No.2(1993), pp. 159-167.

(17) Olsson, A., Stemme, G., Stemme, E., Diffuser-element design investigation for valve-less pumps, Sensors and Actuators A, Vol.57, No.2(1996), pp. 137-143.

(18) Pan, L., Ng, T., Wu, X., Lee, H., Analysis of valveless micropumps with inertial effects, J. Micromech. Microeng., Vol.13, No.3(2003), pp.390-399.

(19) Mane, P., Mossi, K., Bryant, R., Synthetic jets with piezoelectric diaphragms, Proceedings of SPIE, Vol.5761. (2005-9), pp.233-243.

(20) Uehara, M., Shinshi, T., Characteristics of Nd-Fe-B/Ta Multilayered Permanent Magnet Thin-films and Their Application to Magnetic Devices, Hitachi Metals Technical Review, Vol.28(2012), pp.14-19. 